\title{
Latent class analysis of exposure to childhood trauma and health risks among justice-involved youth: Gender differences
}

\author{
Richard Dembo $^{*}$, Julie M Krupa ${ }^{2}$, Jennifer Wareham ${ }^{3}$, Jessica Faber ${ }^{4}$, Ralph J DiClemente ${ }^{5}$ and James Schmeidler ${ }^{6}$ \\ ${ }^{1}$ University of South Florida, Tampa, Florida, USA \\ ${ }^{2}$ Michigan State University, East Lansing, Michigan, USA \\ ${ }^{3}$ Wayne State University, Detroit, Michigan, USA \\ ${ }^{4}$ Agency for Community Treatment Services, Inc., Tampa, Florida, USA \\ ${ }^{5}$ New York University, New York, New York, USA \\ ${ }^{6} \mathrm{Mt}$. Sinai School of Medicine, New York, New York, USA
}

\begin{abstract}
Research indicates juvenile justice-involved youth experience increased risk of exposure to childhood trauma and health risks. Little is known about the heterogeneity in trauma and health risk experiences among delinquent youth, especially across gender. The current study uses latent class analysis to examine typologies of selfreported exposure to trauma and health risks among a sample of 435 female and 1,198 male juvenile offenders. This study also explored associations between the variables used in the latent class analyses and key socio-demographic variables. The findings suggest the presence of three groups of trauma and health risk behaviors within the gender groups. For females, the three subgroups demonstrated linear trends in increasing prevalence of trauma and health risk. For males, the three subgroups reflected a generally low-risk group, a group with high rates of marijuana use and risky sexual behaviors, and a group with high rates of depression, family problems, sexual assault victimization, and bullying. The analyses for the covariates suggested racial differences for certain forms of trauma and health risks. The findings suggest gendered intervention strategies should be considered for justice-involved youth.
\end{abstract}

\section{Introduction}

Youth involved in the juvenile justice system remain a significantly underserved population at markedly elevated risk for multiple problems, involving traumatizing experiences, substance abuse, mental health, and sexually transmitted infections, including HIV (human immunodeficiency virus) [1-3]. Many of these youth have experienced painful childhoods involving family substance misuse, parent incarceration [4,5]. As Ford, et al. [5] note, detained youth who are exposed "to multiple types of victimization, interpersonal violence, and loss ... have more severe emotional, behavioral, interpersonal, and school problems than other justice-involved youth." A "trauma informed" focus is needed to address the effects of traumatic experiences on youth, as evidence indicates over $90 \%$ of justice-involved youth report exposure to at least one kind of traumatizing experience, with exposure to multiple traumas being common [6-10]. The present study examined the heterogeneity in traumatic and at-risk experiences among a sample of justice-involved adolescents.

\section{Justice-involved youth risk factors}

Research has identified several risk factors associated with juvenile justice involvement. For instance, adolescents involved in the juvenile justice system experience a disproportionate, high prevalence of serious mental health issues, substance use, and other problems [2,3,11-13]. Research indicates depressed mood is associated with conduct problems, which tend to overlap with juvenile delinquency. Studies of justice-involved youth demonstrate higher prevalence rates of depression and other mental health disorders, compared to those among the general population of youth $[3,11,14,15]$. For example, Teplin, et al. [2] found two-thirds of detained boys and three-quarters of detained girls were experiencing psychiatric disorders. In general, girls are twice as likely as boys to develop major depressive disorders and other serious affective problems [16]. Furthermore, depression has been linked to risky sexual behaviors and substance use among justiceinvolved adolescents $[3,11,17]$.

Mental health problems are associated with the use of marijuana, a drug most often used by justice-involved youth [18-21]. For example, longitudinal studies of adolescents demonstrate increased marijuana use is related to increased symptoms of depression over time [22,23]. When examining sex differences, most studies find the relationship between depression and marijuana use is stronger for boys, than girls $[24,25]$. Studies of justice-involved youth have also revealed comorbidity in marijuana use and depression [11,17].

In addition to experiencing problems with substance use and mental health problems, justice-involved adolescents are often victims

${ }^{\star}$ Correspondence to: Richard Dembo, Department of Criminology, University of South Florida, 4202 E. Fowler Ave, SOC 107, Tampa, Florida, 33620, USA, Tel: (813)943-7116; Fax: (813)354-0740; E-mail: rdembo@usf.edu

Key words: trauma, health risks, delinquency, sexual risk behaviors, STD, drug use, sexual minority, sexual assault, bullying

Received: June 05, 2019; Accepted: June 13, 2019; Published: June 17, 2019 
of harassment and assault. Bullying is quite prevalent in the U.S. A 2015 national survey found $20 \%$ of high school students reported being bullied on school grounds in the previous 12 months [26]. Bullying has been found to be related to other forms of problem behavior, including vandalism, shoplifting, and fighting (Office of Juvenile Justice and Delinquency Prevention [OJJDP], 2001); and can be seen as a precursor to more antisocial and rule breaking behavior [27]. In addition, bullying has been found to lead to adult criminal behavior [28]. Justice-involved youth have elevated prevalence rates of bullying experiences [5,29-31].

Involvement in bullying has also been found to be related to mental health problems, including depression, as well as substance useespecially alcohol and cannabis use/abuse [31-34]. Bully-victims (those who bully others and are bullied themselves) appear to have the highest prevalence of these associated problems [34]. Research has indicated that boys are more likely than girls to be the targets and perpetrators of bullying [35-37].

Research on justice-involved youths has also identified sexual experiences and behaviors as correlates of delinquency. Child sexual abuse is more prevalent than generally realized, with an estimated 1 in 7 girls and 1 in 25 boys being sexually victimized prior to age 18 [38]. Justice-involved youth have an elevated rate of sexual abuse experiences [5]. National crime statistics indicate juveniles comprise two-thirds of the victims of sex crimes; and the younger the child the greater the odds the abuser is a family member [39,40]. Sexually abused children are at increased risk of suffering additional negative consequences, such as mental health issues, risky sexual behavior, including sexually transmitted disease (STDs) and HIV, alcohol and drug abuse problems, and bullying [4,41-45]. In fact, substance abuse and mental health problems are a common consequence for adult survivors of child sexual abuse $[47,48]$.

In addition, justice-involved youths' adverse family situations need to be considered in relation to the associated health risks they often develop in response to, or as a means of coping with, stressful experiences. A family's well-being is essential for a child's healthy psychosocial adjustment $[49,50]$. Stressful family experiences include parental incarceration, victimization, and family disruption [51-56].

Family member alcohol and other drug abuse also constitute significant factors in the development of justice-involved youths' substance use, delinquency, and sexual risk behaviors. For example, growing up in a household where alcohol is misused or illicit drugs are used by family members is associated with the child's own drug use in later life, and increases their risk of mental health problems (e.g., depression), physical or sexual violence victimization, bullying, and other maltreatment [57-65].

\section{Sexual orientation}

Although not commonly regarded as a youth risk factor, available evidence suggests lesbian, gay, bisexual, transgender, and queer (LGBTQ) youth are overrepresented in the juvenile justice system, and often bring with them serious mental health issues. A 2015 nationwide survey of high school students found LGB youth represent approximately $12 \%$ of girls and less than $5 \%$ of boys [66]. Research indicates that large proportions of sexual minority youth are involved in the justice system. A study of six juvenile detention facilities across the U.S. found LGB youth represented $11 \%$ of juvenile detainees, with sexual minority girls and boys comprising $23 \%$ and $8 \%$ of detainees, respectively [67]. Another survey of juvenile detention centers reported $32 \%$ of girls and $6 \%$ of boys identified as sexual minorities (i.e., gay, lesbian, bisexual, or queer/questioning) [68]. Further, a nationally representative survey of juveniles held in correctional facilities reported $39 \%$ of girls and $3 \%$ of boys were identified as sexual minority [69].

Related research highlights justice-involved LGBTQ youth are among the most troubled youth in society. These youth experience a variety of personal, social, and systemic harms and difficulties that place them at greater risk of finding their way into the justice system. These harms and difficulties include family rejection and placement in the foster care system. Foster care often exposes them to stigma, discrimination, abuse, and victimization from their sexual majority peers (Irvine \& Canfield, 2015), resulting in their being forced out of their homes, running away and becoming homeless [68-72]. Additional victimization commonly occurs while being homeless (ACYF, 2016), as well as involvement in survival crimes, such as shoplifting, trading sex, and drug sales and experiencing the effects of police strategies and discrimination targeting of LGBTQ youth [70-74]. For many LGBTQ youth, the net result of these experiences is entry into the juvenile justice system-where they are at risk of experiencing additional forms of discrimination and harm [75].

\section{Sexual risk behavior}

Justice involved youth also have high rates of involvement in sexual risk behavior and sexually transmitted diseases (STDs) $[3,76]$. They often experience a disproportionate prevalence of HIV/STDs, and engage in sexual risk behaviors associated with adverse health outcomes [3,12,26,77,78]. Nationwide, $11.5 \%$ of high school youth report having sexual intercourse with four or more partners during their lifetime [26]. Gender differences exist in these prevalence rates, with higher rates among boys (ever sexual intercourse: $43.2 \%$; multiple sex partners: $14.4 \%$ ) than girls (ever sexual intercourse: $39.2 \%$; multiple sex partners: $8.8 \%$ ) [26]. When compared to the general population, justice-involved adolescents are at greater risk of engaging in risky sexual behaviors, which increase the chance of acquiring an STD or HIV infection [37,79]. In fact, adolescents are one of the highest risk groups for acquiring STDs and HIV, particularly youths having contact with the juvenile justice system $[37,80,81]$. While girls may be less involved in risky sexual behavior than boys, they experience a disproportionate burden of the adverse health consequences of these behaviors [82].

Adolescents, including justice-involved youth experiencing the problems of risky sexual behaviors and STD infection, are also likely to demonstrate other problems, such as substance use and depression [3]. A 2016, Monitoring the Future survey indicated the annual prevalence of illicit substance use other than marijuana was $5 \%$ for 8 th graders, $10 \%$ for 10th graders, and $14 \%$ for 12 th graders, while the annual prevalence of marijuana use was $9 \%$ for 8 th graders, $24 \%$ for 10 th graders, and $36 \%$ for 12 th graders [83]. Male adolescents are more likely to use substances than female adolescents [83]. Meta-analysis has revealed a small to moderate effect size for the relationship between substance use and risky sexual behaviors among adolescents [84]. Marijuana use, in particular, is associated with risky sexual behaviors, such as sex with partners of unknown HIV status, early initiation of sex, transactional sex (exchanging sex for money, drugs, food), and sex without condom use $[77,85,86]$.

Depression is also linked to risky sexual behaviors and substance use among adolescents. Depressive symptoms appear in both male and female adolescents, but girls are twice as likely as boys to develop major depressive disorders and other serious affective problems [16]. Adolescents involved in the juvenile justice system are even more likely to experience depressive symptoms [2]. 


\section{Gender effects}

It is important to consider gender differences in the multiple problems often experienced by justice-involved youth. As discussed earlier, girls experience higher rates of psychiatric disorders, STDs, the health effects of sexually transmitted diseases, and sexual assaults, than males. On the other hand, boys are more likely to be involved in substance use, and to be the targets and perpetrators of bullying, than girls. The effectiveness of behavioral health services could be improved by greater insight into these relationships, and the prevalence of subgroups of male and female youth reflecting different combinations or patterns of trauma and health risk behaviors [87-89].

\section{Research questions}

Drawing on the above discussed literature, this study addressed three research questions:

1. What subgroups of male and female justice-involved youth reflect combinations or patterns of trauma and health risk behaviors?

2. How prevalent are any subgroups reflecting combinations of trauma and health risk factors?

3. Are there gender group, socio-demographic differences in the combinations of any trauma and health risk factors?

\section{Method}

Project Setting: Juvenile Assessment Center (JAC) Health Coach Services

The study data were collected in an innovative, comprehensive Health Coach service for youth entering a Juvenile Assessment Center (JAC), a centralized intake facility, in a southeastern U.S. city. Every juvenile arrested for a crime in the service area of the JAC is taken to the JAC for intake processing; youths who are charged by the State Attorney's Office but not arrested may also be processed at the JAC. At intake, each youth is assessed for risk and interviewed about her/ his crime by JAC intake personnel, after which s/he is either released to a parent's custody or detained, depending on level of risk and offense. During the intake process at the JAC, youths are also approached by Health Coach service staff. This service has three major goals [90]. First, it offers HIV evidence-based risk reduction information and education to youth using a gendered and developmentally appropriate online curriculum. Second, urinalysis is performed for recent drug use, as well as rapid testing for HIV, urine testing for other STDs, and testing for Hepatitis C, when indicated. Third, the service follows-up with youth and provides prompt, appropriate linkage to treatment for those who are drug-involved, test positive for HIV or other STDs, or screen high on an evidence-based depression inventory [91]. As discussed below, sociodemographic information is collected as well as information on sexual risk behavior, depression, and drug involvement in the past 12 . The Health Coach service involves collaboration with the Department of Health (DOH), and links youth needing follow-up care with community-based services and exposes Health Coach served youth to an evidence-based STD/HIV intervention program. Youth with positive drug test results or elevated depression assessment scoresdiscussed in the measures section-are eligible for referral to an on-site therapist for rapid, follow-up care.

\section{Procedures}

The study data were collected by JAC Health Coaches from youth clients they served. Health Coaches are trained to follow a detailed data collection and service delivery protocol. Data collection and entry are routinely monitored for integrity and quality by the Program Manager. The electronic data from the Health Coaches were de-identified. Then, the de-identified data were given to the research team for analysis purposes; therefore, the Institutional Review Board (IRB) did not consider this a study involving human subjects. The participants were not compensated for their involvement in the study. The intake assessment center is separate from the court process.

The State requires a time limit of six hours to process youth at each of the JACs. The need to adhere to law enforcement booking procedures, as well as Health Coach detailed data collection and service delivery protocols, prevented the use of extensive measures, instead relying primarily on the use of yes/no questions for presence of family and youth problems and experiences. This affects the variability of indicators used in the present study.

\section{Participants}

Participants in the current study received Health Coach services between January 1, 2017 and December 31, 2017. To avoid multiple counting of youth, the initial JAC entry data were used in analyses; over $80 \%$ had one entry. For these multiple entry youth, Health Coach data collected during their first entry were used in the present study. A total of 435 females and 1,198 males were included in the analyses.

Participation in this service was purely voluntary. The State's Public Health law does not require youth 12 years and over to obtain parental consent for STD or HIV testing or treatment. Health Coach staff obtained youth consent prior to initiating services. The participation rate to receive Health Coach services exceeded 96\%. Consenting youth were interviewed by Health Coaches in private offices at the JAC. Since the Health Coach service refusal rate was near zero $(96 \%$ of youth agreed to participate), no socio-demographic and other comparisons were made between youth agreeing and youth declining to receive services.

\section{Socio-demographic characteristics}

Age was included as a continuous variable in number of years. Biological sex (referred to henceforth as gender, though this term is restrictive here) was a dichotomous variable for male biological sex (0) and female biological sex (1). Race/ethnicity was a categorical variable for Hispanic (1), African American (2), White (3), or Other (4). Youth were also asked about their living situation. Few male (13\%) and female (12\%) youth reported living with both biological parents, or birth mother with stepparent or partner ( $17 \%$ and $16 \%$, respectively), but $34 \%$ of male youth and $34 \%$ of female youth indicated they were living with their birth mother alone. Few male and female youth were living in other situations (e.g., birth father alone, grandparents). Accordingly, the living situation variable was coded as $1=$ living with birth mother alone or $0=$ other arrangement. None of the sociodemographic variables had missing data.

\section{Family problems}

Dichotomous variables were created to capture affirmative (1) and negative (0) responses to three questions about the youth's family members. These three questions were: "Has any member of your family had problems with alcohol;" "Has any member of your family had problems with drug abuse;" and "Have either biological parent spent time in jail or prison?" 


\section{Substance use}

Two measures of substance use were included in the analyses. First, drug assay results were obtained from urine analyses (UA) conducted at the $\mathrm{DOH}$ lab facility. At the $\mathrm{DOH}$ testing lab, urine specimens were tested for seven drugs using the enzyme multiplied immunoassay technique (EMIT) procedure: methamphetamines, cocaine, opiates, marijuana, spice (UR144 metabolite), alcohol, and benzodiazepines. Very few youths were found to be drug positive for any drug other than marijuana (range $0 \%$ to $3 \%$ ); hence, only UA results for marijuana were included in the present study. The cutoff level for a positive for marijuana test is $50 \mathrm{ng} / \mathrm{ml}$ of urine. The marijuana UA results were dichotomized $(0=$ negative, $1=$ positive $)$.

The second measure of substance use reflected the severity of youths' perceptions of problems associated with their drug use. Drug problems were measured using the Texas Christian University (TCU) Drug Screen V instrument, which is a self-report instrument probing use of various drugs and consequences of use based on DSM-V criteria during the past 12 months [92]. Responses to this instrument are scored to produce a single total score ranging from 0 to 11 , which is then converted to three severity categories corresponding to DSM-V criteria: $1=$ mild disorder with score of 2-3 points (i.e., presence of 2-3 symptoms), 2 = moderate disorder with score of $4-5$ points, and $3=$ severe disorder with score of 6 or more points. Another "severity" category was created corresponding to the presence of fewer than 2 points: $0=$ no disorder.

\section{Sexual risk behavior}

Two measures of risky sexual behavior were included. The number of sexual partners is widely used as a sexual risk behavior measure [93]. Number of sexual partners was measured as a single item appropriated from the Youth Risk Behavior Survey (CDC, 2016): "During the past three months, with how many people have you had sexual intercourse?" Response choices were "I have never had sexual intercourse," "1 person," "2 people," "3 people," "4 people," "5 people," and " 6 or more people" [26]. The sexual partners variable was coded as 0 for "never had sexual intercourse" to 6 for " 6 or more people" in the analyses.

The second sexual risk variable, STD status, was measured by a non-invasive, FDA)-approved, urine-based nucleic acid test, GenProbe APTIMA Combo 2 Assay, for chlamydia and gonorrhea. The sensitivity of GenProbe's test has been shown to be superior to culture and direct specimen tests. For chlamydia, the sensitivity and specificity of the GenProbe urine-based test are $95.9 \%$ and $98.2 \%$, respectively; and for gonorrhea, they are $97.8 \%$ and $98.9 \%$, respectively (Chacko, Barnes, Wiemann, \& DiClemente, 2004) [94]. The STD status measure was a dichotomous variable for positive (1) for any STD (i.e., chlamydia, gonorrhea, or both) and negative (0) for all STD tests.

\section{Depression}

Depressive symptoms were measured using the 8-item, shortened version of the widely used 20-item Center for Epidemiological Studies Depression Scale [95]. The 8-item depression measure has been found to be psychometrically sound for use among justice-involved youth [96]. The eight items asked of participants were: "I felt I could not shake off the blues even with the help from my family and friends;" "I felt sad;" "I felt depressed;" "I thought my life had been a failure;" "I felt fearful;" "My sleep was restless;" "I felt lonely;" and "I had crying spells." The items were asked regarding the past week and response options were "less than one day" (0), "1-2 days" (1), "3-4 days" (2), and "5-7 days" (3). An additive index for depressive symptoms was created from the items with total scores ranging from 0 to 24 . Previous research has found that a depression measure score of 7 or higher is a threshold score indicative of potentially needing clinical intervention $[97,98]$. Therefore, the depression index was dichotomized for subsequent analysis as scores 0-6 (0) and scores 7-24 (1).

\section{Trauma victimization}

Finally, two indicators of trauma victimization were included. First, youths were asked to self-report their experience of being sexually assaulted. Specifically, they were asked: "Have you ever been sexually assaulted?" The sexual assault victimization variable was dichotomous based on responses of yes (1) and no (0). Second, youths were asked to self-report involvement with bullying. Bullying involvement was based on responses to the following question: "Have you ever been involved in bullying?" Responses to this dichotomous question were no (0) and yes (1). The question about bullying did not distinguish among perpetrators, victims, and perpetrators/victims of this behavior, only that some form of bullying occurred; hence, this variable can reflect both victimization and/or perpetration.

\section{Sexual orientation}

Sexual orientation was assessed with a single item: "Which of the following best describes you?" Response options were "Bisexual," "Gay or Lesbian," "Heterosexual (straight)," or "Not Sure." Youth who responded as bisexual, gay, or lesbian (LGB) were coded as sexual minority (1), while those who responded as heterosexual were coded as non-sexual minority (0). Most youths in the sample identified their sexual orientation as heterosexual, gay or lesbian, or bisexual. Very few female $(n=12)$ and male $(n=2)$ youths reported they were "not sure" about their sexual orientation; hence, these few youths were excluded from the analyses.

The distribution of sexual orientation across gender was $1 \%$ of males and $18 \%$ of females identified as bisexual, $1 \%$ of males and $8 \%$ of females identified as gay or lesbian, and $98 \%$ of males and $71 \%$ of females identified as heterosexual. Thus, only $2 \%$ of males were sexual minority compared to $29 \%$ of females in this sample of arrested youth. The proportion for females is comparable to other studies of sexual minority status in justice-involved youth, but low for males. Discussion with the Health Coach program manager indicated male youth were more embarrassed or reluctant to report their sexual orientation, whereas female youth were more willing to share this information. The reader is cautioned to regard the male sexual orientation data as a likely underestimate.

\section{Analysis strategy}

The analyses proceeded in several stages. First, descriptive comparisons were made between male and female youths on sociodemographic variables and the variables involved in the latent class analysis. Second, a latent class analysis (LCA) was completed on the following variables: number of sexual partners in past 3 months, elevated depression, UA marijuana test results, STD status, sexual orientation, drug use severity category, family member problems with alcohol, family member problems with other drug abuse, whether a biological parent spent time in jail or prison, sexual assault victimization, and involved in bullying.

The LCAs were performed using Mplus Version 8.0 [99]. LCA seeks to identify an underlying classification of entities (e.g., individuals) which are related to manifest indicators in probabilistic terms [100]. In particular, the LCA model is useful when studying a heterogeneous 
population. The use of LCA in this study was exploratory in nature, that is, without specification of hypotheses relating to the values of the conditional or latent class probabilities. The objective of this analysis was to examine the heterogeneity and magnitude of the LCA variables among subgroups of male and female youths, assuming heterogeneity existed. Multi-group LCA (using the known class function in Mplus) was employed for this purpose to explore heterogeneity across gender (sex). MLR (maximum likelihood parameter estimates with standard errors and a chi-square statistic that are robust to non-normality and non-independence of observations) was used as an estimator [99]. The Mplus feature for ML estimation of missing values (FIML) was used to treat any missing data [99]. Figure 1 illustrates the model that was estimated. Finally, following the LCA estimations, an additional analysis was performed. For each gender group, the relationships of age, living with biological mother only, being African American, Hispanic, or White and the variables in the latent class model were studied.
For missing data, other than the UA marijuana test results and STD test results $(\mathrm{n}=219$ and $\mathrm{n}=358$ cases, respectively), very few cases were missing information on the variables included in the analyses (14 cases or fewer). Hence, an additional examination was conducted to determine whether cases with valid or missing data on UA marijuana test results or STD test results differed regarding other measures in our study [101]. Low magnitudes of relationship were found, suggesting that cases not included in the analyses did not introduce systematic bias. There was a sizable correlation between valid and missing data relating to the marijuana test results and STD test results $(\mathrm{r}=.406, \mathrm{p}<.001)$; however, since the youths' urine specimens were split for drug and STD testing, this relationship was an artifact of the testing procedure, not a reflection of systematic bias. Hence, the Mplus data imputation procedure was used, in which each missing value was replaced by a set of plausible values drawn from their predictive distribution to estimate the values of the missing data $[102,103]$.

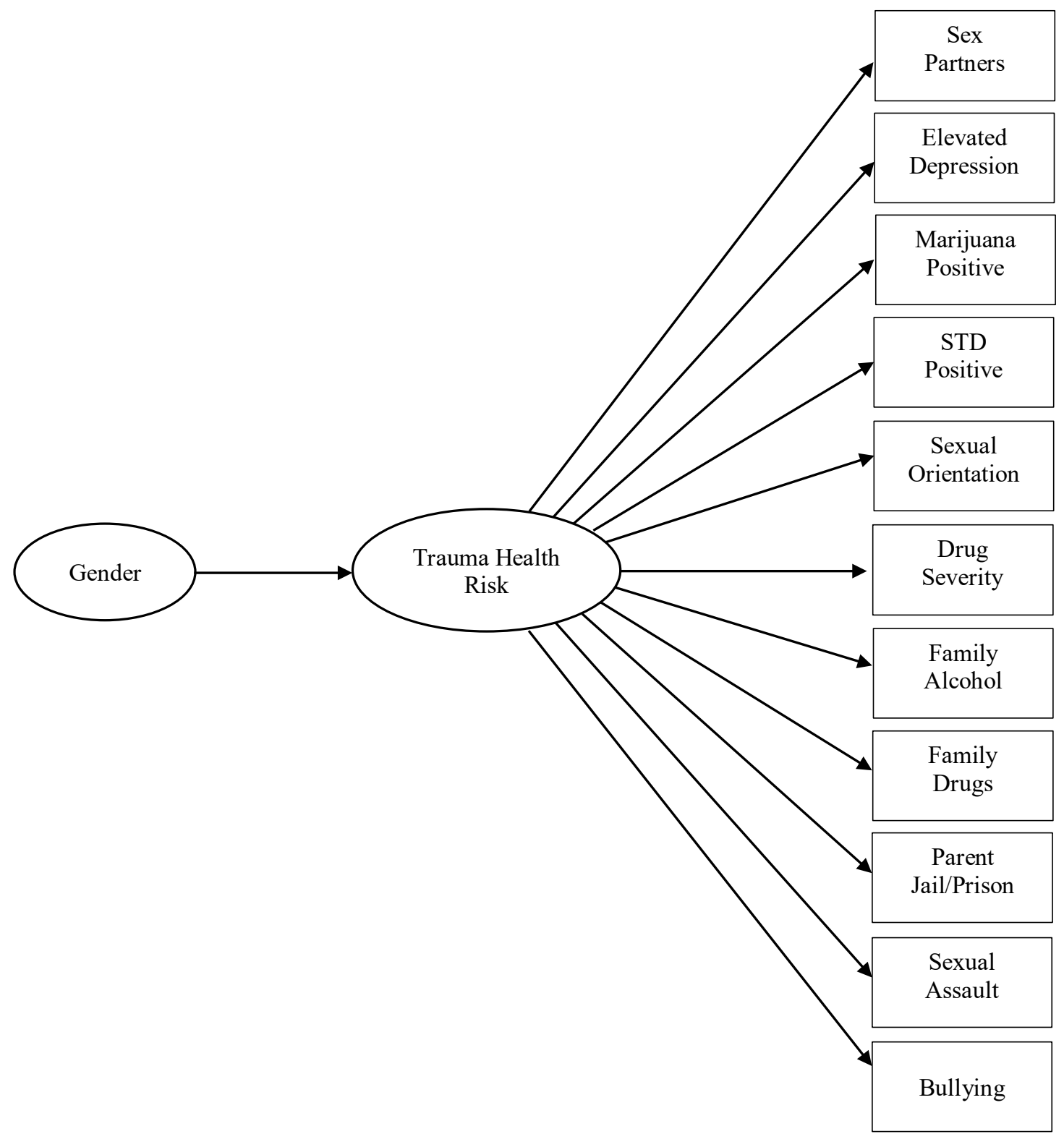

Figure 1. Multi-group latent class model. Gender serves as a known class for estimating the latent class analysis. The latent class is estimated for $k$ classes comprised of the observed variables for trauma experiences and health risks: number of sex partners, elevated depression, marijuana positive, STD positive, sexual orientation, drug severity category, family member's alcohol problem, family member's drug problem, parent's incarceration, sexual assault victimization, and involvement in bullying 


\section{Assessing LCA model fit}

Several indictors were used to assess LCA model fit: (1) the classification table, with high diagonal values and low off-diagonal values indicating good classification quality; (2) entropy, with values ranging from 0 to 1 , with scores close to 1 indicating clear classifications; (3) Akaike Information Criterion (AIC), Bayesian Information Criterion (BIC), and the sample size adjusted BIC (saBIC), with lower AIC, BIC, and saBIC, scores (i.e., closest to zero) indicating a better fit of the model; (4) the fit of the model to the univariate and bivariate frequency tables, with smaller standardized residuals between the observed and estimated (expected) probabilities indicating better model fit [99]. The mixture model with known classes precluded use of the Lo-MendellRubin likelihood ratio test of model fit; and having more than one categorical latent variable prevented use of a parametric bootstrapped likelihood test of model fit. An additional criterion in assessing fit was the substantive meaningfulness of the LCA solution [104-106].

\section{Results}

\section{Socio-demographic and health risk factor comparisons}

As can be seen in Table 1, the male youth were slightly older than female youth. A larger percent of females was White, than males. Females reported larger percentages of family problems (alcohol abuse, other drug abuse, biological parent in jail or prison), than males. Females had a higher STD positive rate than males, while males had a higher UA marijuana test positive rate than the females. Males reported a larger average number of past three-month sexual partners, than the females. Finally, females had higher elevated depression rates, a larger percent who reported a minority sexual orientation, higher rates of being sexually assaulted, and greater involvement in bullying, than males.

\section{LCA fit statistics}

The LCA fit statistics are shown in Table 2. Given the limited number and distribution of cases across the various categorical variables, up to a three class LCA solution could be reliably estimated. The three-class solution seemed to fit the data best: (1) the classification table indicated very high diagonal values (>.90), and only two off diagonal values greater than 0.08 ; (2) a very high entropy value of 0.89 was obtained; (3) the three class solution had lower AIC, BIC, and saBIC values, than the one and two-class solution; (4) relatively few significant univariate and bivariate frequency standardized residuals were found; and (5) the three-class solution provided a more substantively meaningful fit, than the two-class solution. As a final check on the results, the analyses were re-estimated with double the random starts, to confirm the best log likelihood was obtained and replicated. The findings indicated this to be the case.

\section{Three-class LCA findings}

The three-class LCA results, in probability scale, are shown in Table 3. Different results were found for female and male youth in the study. Among girls, and with few exceptions, there was a linear trend in the prevalence of the risk factors progressing from the low risk, through the moderate risk, and to the high risk classes. An important feature of this result is that the various risk factors cluster together among the girls; $3 \%$ of the girls were in the elevated risk group, $37 \%$ were in the moderate risk group, and $60 \%$ were in the low risk group. These three groups accounted for $1 \%, 10 \%$, and $16 \%$, respectively, of all youth involved the study.
Table 1. Covariate Comparison between Female and Male Youth

\begin{tabular}{|c|c|c|}
\hline & $\begin{array}{l}\text { Females } \\
(n=423 \text { to } 435)\end{array}$ & $\begin{array}{l}\text { Males } \\
(n=1196 \text { to } 1198)\end{array}$ \\
\hline Age, $M(S D)$ & $15.64(1.475)$ & $15.80(1.423) *$ \\
\hline Living with mother only & $54.9 \%$ & $55.8 \%$ \\
\hline \multicolumn{3}{|l|}{ Race/ethnicity: } \\
\hline African American & $49.7 \%$ & $54.6 \%$ \\
\hline White & $32.2 \%$ & $24.7 \% * *$ \\
\hline Hispanic & $13.8 \%$ & $15.0 \%$ \\
\hline Other & $3.6 \%$ & $5.7 \%$ \\
\hline Family alcohol abuse problem & $25.3 \%$ & $12.1 \% * * *$ \\
\hline Family other drug abuse problem & $26.7 \%$ & $12.4 \% * * *$ \\
\hline Biological parent in jail/prison & $64.4 \%$ & $57.0 \% * *$ \\
\hline \multicolumn{3}{|l|}{ Drug use severity: } \\
\hline None & $92.2 \%$ & $93.7 \%$ \\
\hline Mild & $5.1 \%$ & $3.7 \%$ \\
\hline Moderate & $0.9 \%$ & $1.3 \%$ \\
\hline Severe & $1.8 \%$ & $1.3 \%$ \\
\hline \multirow[t]{2}{*}{ STD positive } & $12.1 \%$ & $6.4 \% * * *$ \\
\hline & $(n=348)$ & $(n=927)$ \\
\hline \multirow[t]{2}{*}{ Marijuana positive } & $43.3 \%$ & $54.5 \% * * *$ \\
\hline & $(n=372)$ & $(n=1042)$ \\
\hline Number of sexual partners past 3 months, $M(S D)$ & $0.67(1.067)$ & $0.89(1.305) * *$ \\
\hline Elevated depression & $20.5 \%$ & $6.0 \% * * *$ \\
\hline Sexual minority orientation & $27.0 \%$ & $1.8 \% * * *$ \\
\hline Been sexual assaulted & $19.5 \%$ & $2.4 \% * * *$ \\
\hline Been involved in bullying & $35.9 \%$ & $16.4 \% * * *$ \\
\hline
\end{tabular}

Note. $\mathrm{STD}=$ sexually transmitted disease. Two-tailed $p$-values: $* p<.05 ; * * p<.01 ; * * p<.001$.

Table 2. Latent Class Analysis Fit Statistics $(n=1633)$

\begin{tabular}{|l|l|l|l|l|}
\hline & $\begin{array}{l}\text { Akaike } \\
\text { (AIC) }\end{array}$ & $\begin{array}{l}\text { Bayesian } \\
\text { (BIC) }\end{array}$ & $\begin{array}{l}\text { Sample Size } \\
\text { Adjusted BIC }\end{array}$ & Entropy \\
\hline 1 Class & 19959.66 & 20110.81 & 20021.86 & -- \\
\hline 2 Classes & 18970.70 & 19272.99 & 19095.09 & 0.989 \\
\hline 3 Classes & 18483.30 & 18936.74 & 18669.89 & 0.887 \\
\hline 4 Classes & \multicolumn{3}{l|}{ Could not be reliably estimated } \\
\hline
\end{tabular}

The LCA results for the boys reflected a more differentiated pattern. As shown in Table 4, distinct subsets of risk factors were identified. First, there was a subgroup of male youth (18\% of cases overall and $24 \%$ among males) reflecting elevated depression, family problems (especially a biological parent spending time in jail or prison), sexual assault victimization, and involvement in bullying. A second male subgroup, accounting for $7 \%$ of all cases and $9 \%$ of male youth, reflected marijuana use and involvement in sexual risk behavior with a high average number of sexual partners in the past three months and a high STD positive rate. A third male subgroup, accounting for nearly half of all youth in the study and $66.8 \%$ of male youth, had-with few exceptions-lower levels of prevalence on the various risk factors than the other two youth subgroups. It should be noted that the standard errors for the third male subgroup were, in general, low and near zero for elevated depression, sexual orientation, and TCU drug severity screen scores. Hence, their critical ratios should be considered with some caution.

\section{Relationship of covariates to health risk variables}

This study also sought to assess, separately for males and females, the relationship of age, living with mother only, and race/ethnicity to the various risk factors. As shown in Table 5, among females, a number of significant relationships were found. However, with four exceptions (4 of 55 [7\%] correlations), the magnitude of these relationships was quite 
small-each explaining less than $9 \%$ of the variance. A similar covariate situation was found among the males. Here, 8 of 55 correlations explained more than $10 \%$ of the variance, and the magnitude of the remaining covariate relationships was, again, small. At the same time, two patterns of relationships could be discerned: White females and males reported more family alcohol and other drug problems, sexual assault, and bullying involvement, and African-American female and male youth reported fewer family alcohol and other drug problems (and for African American males, fewer sexual assault and bullying issues), than other youth in the study. Few other relationships were patterned or explained more than $10 \%$ of the variance. Therefore, based on the aforementioned results, with the exception of the covariate relationships just noted, the covariates were not significant factors influencing the various latent classes.

Table 3. Latent Class Results for Females in Probability Space

\begin{tabular}{|c|c|c|c|c|c|c|}
\hline & \multicolumn{2}{|c|}{$\begin{array}{l}\text { Elevated Risk } \\
(n=15,1 \%)\end{array}$} & \multicolumn{2}{|c|}{$\begin{array}{l}\text { Moderate Risk } \\
(n=160,10 \%)\end{array}$} & \multicolumn{2}{|c|}{$\begin{array}{l}\text { Low Risk } \\
(n=260,16 \%)\end{array}$} \\
\hline & Estimate & SE & Estimate & SE & Estimate & SE \\
\hline $\begin{array}{l}\text { Sexual partners } \\
(M)\end{array}$ & $5.310^{* * *}$ & 0.379 & $0.624 * * *$ & 0.060 & $0.442 * * *$ & 0.038 \\
\hline \multicolumn{7}{|l|}{$\begin{array}{l}\text { Elevated } \\
\text { depression: }\end{array}$} \\
\hline No & $0.340^{*}$ & 0.137 & $0.632 * * *$ & 0.044 & $0.922 * * *$ & 0.033 \\
\hline Yes & $0.660 * * *$ & 0.137 & $0.368 * * *$ & 0.044 & $0.078 *$ & 0.033 \\
\hline \multicolumn{7}{|l|}{ Marijuana UA: } \\
\hline Negative & $0.472 * *$ & 0.157 & $0.561 * * *$ & 0.050 & $0.576^{* * *}$ & 0.036 \\
\hline Positive & $0.528 * * *$ & 0.157 & $0.439 * * *$ & 0.050 & $0.424 * * *$ & 0.036 \\
\hline \multicolumn{7}{|l|}{ STD results: } \\
\hline Negative & $0.685 * * *$ & 0.131 & $0.918 * * *$ & 0.028 & $0.869 * * *$ & 0.025 \\
\hline Positive & $0.315^{*}$ & 0.131 & $0.082 * *$ & 0.028 & $0.131 * * *$ & 0.025 \\
\hline \multicolumn{7}{|l|}{$\begin{array}{l}\text { Sexual } \\
\text { orientation: }\end{array}$} \\
\hline Majority & $0.315^{*}$ & 0.134 & $0.606 * * *$ & 0.044 & $0.829 * * *$ & 0.029 \\
\hline Minority & $0.685^{* * *}$ & 0.134 & $0.394 * * *$ & 0.044 & $0.171^{* * *}$ & 0.029 \\
\hline \multicolumn{7}{|l|}{$\begin{array}{l}\text { Drug severity } \\
\text { score: }\end{array}$} \\
\hline None & $0.660 * * *$ & 0.118 & $0.885^{* * *}$ & 0.029 & $0.959 * * *$ & 0.013 \\
\hline Mild & 0.068 & 0.065 & $0.080 * * *$ & 0.024 & $0.032 * *$ & 0.012 \\
\hline Moderate & 0.068 & 0.064 & 0.014 & 0.010 & 0.003 & 0.004 \\
\hline Severe & $0.204 \uparrow$ & 0.105 & $0.021 \dagger$ & 0.012 & 0.006 & 0.006 \\
\hline \multicolumn{7}{|l|}{$\begin{array}{l}\text { Family alcohol } \\
\text { problems: }\end{array}$} \\
\hline No & $0.361^{* *}$ & 0.133 & $0.456 * * *$ & 0.074 & $0.948 * * *$ & 0.020 \\
\hline Yes & $0.639 * * *$ & 0.133 & $0.544 * * *$ & 0.074 & $0.052 * *$ & 0.020 \\
\hline \multicolumn{7}{|l|}{$\begin{array}{l}\text { Family drug } \\
\text { problems: }\end{array}$} \\
\hline No & $0.294 *$ & 0.127 & $0.341 * * *$ & 0.099 & 1.000 & 0.000 \\
\hline Yes & $0.706^{* * *}$ & 0.127 & $0.659 * * *$ & 0.099 & 0.000 & 0.000 \\
\hline \multicolumn{7}{|l|}{$\begin{array}{l}\text { Parent in jail/ } \\
\text { prison: }\end{array}$} \\
\hline No & $0.203 \dagger$ & 0.104 & $0.193 * * *$ & 0.039 & $0.465 * * *$ & 0.035 \\
\hline Yes & $0.797 * * *$ & 0.104 & $0.807 * * *$ & 0.039 & $0.535^{* * *}$ & 0.035 \\
\hline \multicolumn{7}{|l|}{$\begin{array}{l}\text { Sexually } \\
\text { assaulted: }\end{array}$} \\
\hline No & $0.271 *$ & 0.120 & $0.651 * * *$ & 0.046 & $0.929 * * *$ & 0.035 \\
\hline Yes & $0.729 * * *$ & 0.120 & $0.349 * * *$ & 0.046 & $0.071^{*}$ & 0.035 \\
\hline \multicolumn{7}{|l|}{$\begin{array}{l}\text { Involved in } \\
\text { bullying: }\end{array}$} \\
\hline No & $0.476^{* * *}$ & 0.147 & $0.467 * * *$ & 0.047 & $0.758 * * *$ & 0.042 \\
\hline Yes & $0.524 * * *$ & 0.147 & $0.533 * * *$ & 0.047 & $0.242 * * *$ & 0.042 \\
\hline
\end{tabular}

Note. $\mathrm{UA}=$ urinalysis; $\mathrm{STD}=$ sexually transmitted disease. Two-tailed $p$-values: $\uparrow p<.10$; $* p<.05 ; * * p<.01 ; * * * p<.001$.
Table 4. Latent Class Results for Males in Probability Space

\begin{tabular}{|c|c|c|c|c|c|c|}
\hline & \multicolumn{2}{|c|}{$\begin{array}{l}\text { High Depression, } \\
\text { Family Problems, } \\
\text { Sexual Assault, \& } \\
\text { Bullying } \\
(n=\mathbf{2 8 9}, \mathbf{1 8 \%})\end{array}$} & \multicolumn{2}{|c|}{$\begin{array}{l}\text { High Marijuana \& } \\
\text { Sexual Risk Behavior } \\
(n=109,7 \%)\end{array}$} & \multicolumn{2}{|c|}{$\begin{array}{l}\text { Low Risk } \\
(n=800,49 \%)\end{array}$} \\
\hline & Estimate & SE & Estimate & SE & Estimate & SE \\
\hline $\begin{array}{l}\text { Sexual partners } \\
(M)\end{array}$ & $0.563 * * *$ & 0.055 & $4.213 * * *$ & 0.156 & $0.552 * * *$ & 0.032 \\
\hline \multicolumn{7}{|l|}{$\begin{array}{l}\text { Elevated } \\
\text { depression: }\end{array}$} \\
\hline No & $0.818^{* * *}$ & 0.028 & $0.918 * * *$ & 0.027 & $0.987 * * *$ & 0.007 \\
\hline Yes & $0.182 * * *$ & 0.028 & $0.082 * *$ & 0.027 & $0.013^{*}$ & 0.007 \\
\hline \multicolumn{7}{|c|}{ Marijuana UA: } \\
\hline Negative & $0.548 * * *$ & 0.039 & $0.362 * * *$ & 0.052 & $0.434 * * *$ & 0.022 \\
\hline Positive & $0.452 * * *$ & 0.039 & $0.638 * * *$ & 0.052 & $0.566 * * *$ & 0.022 \\
\hline \multicolumn{7}{|l|}{ STD results: } \\
\hline Negative & $0.956 * * *$ & 0.016 & $0.844 * * *$ & 0.043 & $0.941 * * *$ & 0.010 \\
\hline Positive & $0.044 * *$ & 0.016 & $0.156^{* * *}$ & 0.043 & $0.059^{* * *}$ & 0.010 \\
\hline \multicolumn{7}{|l|}{$\begin{array}{l}\text { Sexual } \\
\text { orientation: }\end{array}$} \\
\hline Majority & $0.956 * * *$ & 0.014 & 1.000 & 0.000 & $0.990 * * *$ & 0.004 \\
\hline Minority & $0.044 * *$ & 0.014 & 0.000 & 0.000 & $0.010 *$ & 0.004 \\
\hline \multicolumn{7}{|c|}{\begin{tabular}{|l|l} 
Drug severity \\
score:
\end{tabular}} \\
\hline None & $0.889 * * *$ & 0.022 & $0.917 * * *$ & 0.027 & $0.958 * * *$ & 0.008 \\
\hline Mild & $0.051 * * *$ & 0.015 & $0.036^{*}$ & 0.018 & $0.032 * * *$ & 0.007 \\
\hline Moderate & $0.022 *$ & 0.010 & $0.038^{*}$ & 0.019 & $0.006 \dagger$ & 0.003 \\
\hline Severe & $0.038^{* *}$ & 0.013 & 0.009 & 0.010 & $0.005 \dagger$ & 0.003 \\
\hline \multicolumn{7}{|c|}{$\begin{array}{l}\text { Family alcohol } \\
\text { problems: }\end{array}$} \\
\hline \begin{tabular}{|l} 
No \\
\end{tabular} & $0.544 * * *$ & 0.046 & $0.896 * * *$ & 0.032 & $0.998 * * *$ & 0.012 \\
\hline Yes & $0.456 * * *$ & 0.046 & $0.104 * * *$ & 0.032 & 0.002 & 0.012 \\
\hline \multicolumn{7}{|l|}{$\begin{array}{l}\text { Family drug } \\
\text { problems: }\end{array}$} \\
\hline No & $0.524 * * *$ & 0.055 & $0.897 * * *$ & 0.032 & 1.000 & 0.000 \\
\hline Yes & $0.476 * * *$ & 0.055 & $0.103 * * *$ & 0.032 & 0.000 & 0.000 \\
\hline \multicolumn{7}{|l|}{$\begin{array}{l}\text { Parent in jail/ } \\
\text { prison: }\end{array}$} \\
\hline No & $0.256^{* * *}$ & 0.031 & $0.347 * * *$ & 0.048 & $0.504 * * *$ & 0.020 \\
\hline Yes & $0.744 * * *$ & 0.031 & $0.653 * * *$ & 0.048 & $0.496^{* * *}$ & 0.020 \\
\hline \multicolumn{7}{|l|}{$\begin{array}{l}\text { Sexually } \\
\text { assaulted: }\end{array}$} \\
\hline No & $0.910 * * *$ & 0.018 & $0.974 * * *$ & 0.016 & 1.000 & 0.000 \\
\hline Yes & $0.090 * * *$ & 0.018 & 0.026 & 0.016 & 0.000 & 0.000 \\
\hline \multicolumn{7}{|l|}{$\begin{array}{l}\text { Involved in } \\
\text { bullying: }\end{array}$} \\
\hline No & $0.674 * * *$ & 0.036 & $0.885^{* * *}$ & 0.032 & $0.887 * * *$ & 0.015 \\
\hline Yes & $0.326 * * *$ & 0.036 & $0.115 * * *$ & 0.032 & $0.113 * * *$ & 0.015 \\
\hline
\end{tabular}

Note. $\mathrm{UA}=$ urinalysis; STD $=$ sexually transmitted disease. Two-tailed $p$-values: $\uparrow p<.10$ ${ }^{*} p<.05 ; * * p<.01 ; * * * p<.001$.

\section{Discussion}

The results provide clear answers to the three research questions informing this study. There was heterogeneity in the experiences of the justice-involved youths. Distinct subgroups of male and female youth were found reflecting different combinations of the trauma and health risk behaviors. The subgroups differed in prevalence among the two gender groups, with the lower risk latent class subgroups for female and males accounting for the largest proportions of the sample ( $16 \%$ and $49 \%$, respectively). On the other hand, the elevated risk subgroup for females and the marijuana use and sexual risk behavior subgroup for males account for the smallest proportion of each gender group-but appeared to demonstrate the most troubling victimization experiences and exposures to trauma. 
Table 5. Female and Male Covariate Relationships with Latent Class Analysis Variables

\begin{tabular}{|c|c|c|c|c|c|}
\hline & \multicolumn{5}{|c|}{ Females } \\
\hline & Age & Lived with mother & African American & Hispanic & White \\
\hline Elevated depression & $0.146^{*}$ & -0.018 & -0.024 & 0.062 & -0.015 \\
\hline Marijuana positive & $0.291 * * *$ & 0.084 & -0.155 & 0.166 & 0.113 \\
\hline STD positive & $0.234^{* *}$ & 0.103 & -0.072 & -0.113 & 0.102 \\
\hline Sexual partners & $0.260 * * *$ & $-0.145^{*}$ & $-0.213 * * *$ & 0.086 & $0.174 * * *$ \\
\hline Sexual minority orientation & 0.016 & 0.090 & -0.078 & 0.087 & -0.033 \\
\hline Drug use severity & 0.195 & -0.189 & $-0.285 * *$ & $0.275^{*}$ & 0.157 \\
\hline Family alcohol problem & 0.010 & $-0.205^{* *}$ & $-0.402 * * *$ & 0.120 & $0.367 * * *$ \\
\hline Family drug problem & -0.009 & $-0.256^{* * *}$ & $-0.407 * * *$ & 0.062 & $0.377 * * *$ \\
\hline Parent in jail/prison & -0.078 & -0.060 & 0.138 & -0.045 & -0.087 \\
\hline Sexually assaulted & 0.127 & -0.036 & $-0.171^{*}$ & -0.108 & $0.235^{* *}$ \\
\hline \multirow[t]{3}{*}{ Bullying } & $-0.128 *$ & -0.011 & -0.069 & -0.159 & $0.165^{*}$ \\
\hline & \multicolumn{5}{|c|}{ Males } \\
\hline & Age & Lived with mother & African American & Hispanic & White \\
\hline Elevated depression & 0.102 & $-0.160 * * *$ & $-0.233 * * *$ & -0.026 & $0.276^{* * *}$ \\
\hline Marijuana positive & $0.340 * * *$ & 0.008 & 0.068 & 0.028 & -0.071 \\
\hline STD positive & $0.228 * * *$ & 0.043 & $0.216^{* *}$ & $-0.213^{*}$ & -0.128 \\
\hline Sexual partners & $0.283 * * *$ & -0.017 & $0.110 * *$ & -0.052 & -0.064 \\
\hline Sexual minority orientation & 0.107 & 0.064 & -0.168 & -0.013 & $0.254^{*}$ \\
\hline Drug use severity & 0.088 & -0.018 & $-0.287 * * *$ & 0.038 & $0.313^{* * *}$ \\
\hline Family alcohol problem & 0.066 & $-0.175 * * *$ & $-0.403 * * *$ & 0.055 & $0.368 * * *$ \\
\hline Family drug problem & -0.020 & $-0.184 * *$ & $-0.397 * * *$ & 0.011 & $0.430 * * *$ \\
\hline Parent in jail/prison & -0.048 & 0.039 & $0.182 * * *$ & $-0.289 * * *$ & $0.015^{* * *}$ \\
\hline Sexually assaulted & 0.008 & $-0.190^{*}$ & $-0.375^{* * *}$ & -0.181 & $0.412 * * *$ \\
\hline Bullying & $-0.233 * * *$ & -0.024 & $-0.206^{* * *}$ & -0.053 & $0.276^{* * *}$ \\
\hline
\end{tabular}

Note. $\mathrm{STD}=$ sexually transmitted disease. Two-tailed $p$-values: $\dagger p<.10 ; * p<.05 ; * * p<.01 ; * * * p<.001$.

The results indicated different female and male trauma and health risk subgroups in the sample. As noted earlier, among girls there was a general, linear pattern of increasing risk, with girls at higher levels of risk reflecting elevated risk behavior than those at lower levels of risk. This pattern of results indicates a general high degree of interrelationship among the behaviors and experiences examined here. In contrast, three different trauma-health risk subgroups were found among male youth: (1) high depression, family problems, sexual assault victimization, and involvement in bullying, (2) recent marijuana use and involvement in sexual risk behavior, and (3) a generally low risk factor subgroup.

As discussed earlier, the data were examined for socio-demographic differences in the various risk factors for the female and male youth. With the two exceptions discussed previously, the analyses did not indicate patterned, highly related covariate and trauma-health risk variable effects. The reasons why White females and males reported more family alcohol and other drug problems, and African-American female and male youth reported fewer family alcohol and other drug problems, than other youth in the study are unclear, and merit further study. Few studies have examined race/ethnicity differences in exposure to adverse childhood experiences. In a study of health risk factors among a general population sample of adults, Lee, et al. [107] reported higher rates of household alcoholism and drug abuse during childhood among African Americans (alcoholism: 26\%; drug abuse: 16\%) than Whites (alcoholism: 22\%; drug abuse: 9\%). On the other hand, in a study of exposure to childhood trauma and health risk factors among adult prison inmates, Roxburgh, et al. [108] found African American inmates (women: $35 \%$; men: $28 \%$ ) experienced lower rates of childhood exposure to parental substance abuse (drugs and alcohol) than White inmates (women: $45 \%$; men: $38 \%$ ). More research is needed to explore the impact of racial/ethnic differences in the relationship between exposure to adverse family conditions and delinquency/crime.
There were several limitations to this study. First, there were limitations due to the nature of the sample, which consisted of newly arrested youth in one jurisdiction. Hence, the results of the study cannot be generalized to newly arrested youth in other locations or non-justice-involved youths. Future research should replicate this study using different populations of justice-involved youth. Second, with the exception of biological test results for marijuana and STDs, the measures were based on self-reports. At the same time, the prevalence rates of the youths' problems are in line with other studies of justiceinvolved youth, and, in the case of reported parental incarceration, strikingly high. Future research should try to include parent and teacher reports of risk factors and behaviors to explore the validity of these findings. Third, the measures of parental incarceration, family alcohol abuse problems, family drug abuse problems, sexual minority status, involvement in bullying, and being sexually assaulted were based on one dichotomous (yes/no) question. For the reasons discussed earlier (i.e., State mandated time restrictions for juvenile intake), it was not possible to use more elaborate measures of these experiences. Future research should include measures with greater variation to explore differences in magnitude of effects. Third, the analyses were performed on cross-sectional data. Hence, it is not possible to make any causal statements regarding the relationships among the variables studied here. Relatedly, the present study was not able to explore how differentiation in trauma and health risk factors affected the likelihood of future delinquent/criminal behavior. Future research should explore the temporal link between exposure to trauma and health risk factors and delinquency among similar populations of justice-involved youth.

The results highlight the need for differentiated intervention services for female and male youth. Girls may benefit from a more holistic, integrated intervention services at levels of intensity reflecting their degree of health risk. On the other hand, male youth could be 
expected to benefit from more differentiated intervention services targeting the specific trauma-risk factors that are adversely affecting their lives. For populations similar to the one studied here, intervention services for male, justice-involved adolescents should focus on (a) combined services for substance use and risky sexual practices and (b) mental health-oriented services that address exposure to trauma such as sexual assault and bullying.

Studies such as the one we report could be conducted periodically to identify emerging trends, problems, and constellations of issues female and male youth bring with them as they enter the juvenile justice system. Early intervention addressing these issues and problems could be of great benefit in improving their health, reducing recidivism, and helping directing their lives in more salutary directions.

The findings of this study highlight the multiple problems affecting youth entering the juvenile justice system. The overall prevalence rates of a number of these experiences are of serious concern. It is hoped our findings will contribute to the growing literature in this important subject area, and encourage other researchers to elucidate the dynamics underlying the associations we identified. In particular, there is an urgent need to address and remediate the adverse consequences of justice-involved youth trauma issues. Appropriate linkage with care providers at earliest point of contact with the justice system would be a great beginning point to intervene in this process, with its long-term, adverse health consequences.

\section{References}

1. Dembo R, Walters W (2012) Juvenile assessment centers: Early intervention with youth involved in drug use. In Jainchill N (Ed), Understanding and treating adolescent substance use disorders Kingston, NJ: Civic Research Institute pp. 15-28.

2. Teplin LA, Abram KM, McClelland GM, Dulcan MK, Mericle AA (2002) Psychiatric disorders in youth in detention. Arch Gen Psychiatry 59: 1133-1143. [Crossref]

3. Teplin LA, Elkington KS, McClelland GM, Abram KM, Mericle AA, et al. (2005) Major mental disorders, substance use disorders, comorbidity, and HIV-AIDS risk behaviors in juvenile detainees. Psychiatr Serv 56: 823-828. [Crossref]

4. Dembo R, Faber J, Cristiano J, Wareham J, Krupa JM, et al. (2018a) Family problems, mental health and trauma experiences of justice-involved youth. Medical Research Archives 6: 1-23.

5. Ford JD, Cruise KR, Grasso DJ (2017) A study of the impact of screening for polyvictimization in juvenile justice, (No. NOJ 2012-IJ-CX-0046). Washington, DC: US Department of Justice, Office of Justice Programs.

6. Ford JD, Blaustein M (2012) System self-regulation: A framework for traumainformed services in residential juvenile justice programs. Journal of Family Violence 28: 655-677.

7. Ford JD, Kerig PK, Desai N, Feierman J (2016) Psychosocial interventions for traumatized youth in the juvenile justice system: Clinical, research, and legal perspectives. Journal of Juvenile Justice 5: 31-49.

8. Ko SJ, Ford JD, Kassam-Adams N, Berkowitz SJ, Wilson C, et al. (2008) Creating trauma-informed systems: Child welfare, education, first responders, health care, juvenile justice. Professional Psychology-Research and Practice 39: 396-404.

9. Abram KM, Teplin LA, Charles DR, Longworth SL, McClelland GM, et al. (2004) Posttraumatic stress disorder and trauma in youth in juvenile detention. Arch Gen Psychiatry 61: 403-410. [Crossref]

10. Dierkhising CB, Ko SJ, Woods-Jaeger B, Briggs EC, Lee R, et al. (2013) Trauma histories among justice-involved youth: Findings from the National Child Traumatic Stress Network. Eur J Psychotraumatol 4: 1-12. [Crossref]

11. Abram KM, Teplin LA, McClelland GM, Dulcan MK (2003) Comorbid psychiatric disorders in youth in juvenile detention. Arch Gen Psychiatry 60: 1097-1108. [Crossref]

12. Freudenberg N (2009) Incarcerated and delinquent youth. In R. J. DiClemente, J. S Santelli, \& R. A. Crosby (Eds.), Adolescent health: Understanding and preventing risk behaviors (pp. 339-358). San Francisco, CA: Jossey-Bass.
13. McClelland GM, Elkington KS, Teplin LA, Abram KM (2004) Multiple substance use disorders in juvenile detainees. Journal of the American Academy of Child and Adolescent Psychiatry 43: 1215-1224. [Crossref]

14. Angold A, Costello E (1993) Depressive comorbidity in children and adolescents: Empirical, theoretical, and methodological issues. Am J Psychiatry 150: 1779-1791. [Crossref]

15. Capaldi DM1, Stoolmiller M (1999) Co-occurrence of conduct problems and depressive symptoms in early adolescent boys: III. Prediction to young-adult adjustment. Dev Psychopathol 11: 59-84. [Crossref]

16. Lakdawalla Z1, Hankin BL, Mermelstein R (2007) Cognitive theories of depression in children and adolescents: a conceptual and quantitative review. Clin Child Fam Psychol Rev 10: 1-24. [Crossref]

17. Stein LAR, Lebeau R, Colby SM, Barnett NP, Golembeske C, et al. (2011) Motivational interviewing for incarcerated adolescents: Effects of depressive symptoms on reducing alcohol and marijuana use after release. J Stud Alcohol Drugs 72: 497-506. [Crossref]

18. Bovasso G (2001) Cannabis abuse as a risk factor for depressive symptoms. Am J Psychiatry 158: 2033-2037. [Crossref]

19. Chen CY, Wagner F, Anthony J (2002) Marijuana use and the risk of major depressive episode: Epidemiological evidence from the United States National Comorbidity Survey. Social Psychiatry and Psychiatric Epidemiology 37: 199-203. [Crossref]

20. Hallfors DD, Waller MW, Bauer D, Ford CA, Halpern CT (2005) Which comes firs in adolescence--sex and drugs or depression? Am J Prev Med 29: 163-170. [Crossref]

21. McGee R, Williams S, Poulton R, Moffitt T (2000) A longitudinal study of cannabis use and mental health from adolescence to early adulthood. Addiction 95: 491-503. [Crossref]

22. Horwood LJ, Fergusson DM, Coffey C, Patton GC, Tait R, et al. (2012) Cannabis and depression: an integrative data analysis of four Australasian cohorts. Drug Alcohol Depend 126: 369-378. [Crossref]

23. Patton GC, Coffey C, Carlin JB, Degenhardt L, Lynskey M, et al. (2002) Cannabis use and mental health in young people: cohort study. BMJ 325: 1195-1198. [Crossref]

24. Repetto PB, Zimmerman MA, Caldwell CH (2008) A longitudinal study of depressive symptoms and marijuana use in a sample of inner-city African Americans. Journal of Research on Adolescence 18: 421-447.

25. Wilkinson AL, Halpern CT, Herring AH (2016) Directions of the relationship between substance use and depressive symptoms from adolescence to young adulthood. Addict Behav 60: 64-70. [Crossref]

26. Centers for Disease Control and Prevention [CDC] (2016) Youth risk behavior surveillance-United States, 2015. Surveillance Summaries 65: 1-174.

27. Office of Juvenile Justice and Delinquency Prevention [OJJDP] (2001) Addressing the problem of juvenile bullying. OJJDP Fact Sheet, \#27. Washington, DC: U.S. Department of Justice, OJJDP.

28. Olweus D, Limber SP (1999) Bullying in school: Evaluation and dissemination of the Olweus Bullying Prevention Program. American Journal of Orthopsychiatry 80: 124134. [Crossref]

29. Ford JD, Grasso DJ, Hawke J, Chapman JF (2013) Poly-victimization among juvenile justice-involved youths. Child Abuse Negl 37: 788-800. [Crossref]

30. Ireland Jane L, Archer J (2004) Association Between Measures of Aggression and Bullying Among Juvenile and Young Offenders. Aggressive Behavior: Official. Journal of the International Society for Research on Aggression 30: 29-42.

31. Vaughn MG, Fu Q, Bender K, DeLisi M, Beaver KM, et al. (2010) Psychiatric correlates of bullying in the United States: Findings from a national sample. Psychiatr Q 81: 183-195. [Crossref]

32. Coolidge FL, DenBoer JW, Segal DL (2004) Personality and neuropsychological correlates of bullying behavior. Personality and Individual Differences 36: 1559-1569.

33. Kumpulainen K, Rasanen E, Henttonen I (1999) Children involved in bullying: Psychological disturbance and the persistence of the involvement. Child Abuse \& Neglect 23: 1253-1262. [Crossref]

34. Shetgiri R (2013) Bullying and victimization among children. Adv Pediatr 60: 33-51 [Crossref]

35. Nansel TR, Overpeck M, Pilla RS, Ruan WJ, Simons-Morton B, et al. (2001) Bullying behaviors among US youth: Prevalence and association with psychosocial adjustment. JAMA 285: 2094-2100. [Crossref] 
36. Tsitsika AK, Barlou E, Andrie E, Dimitropoulou C, Tzavela EC, et al. (2014) Bullying behaviors in children and adolescents: "an ongoing story". Front Public Health 2: 7. [Crossref]

37. Centers for Disease Control and Prevention (CDC) (2014) Sexually transmitted disease surveillance 2013. Atlanta, GA: U.S. Department of Health and Human Services, Centers for Disease Control and Prevention.

38. Townsend C, Rheingold AA (2013) Estimating a child sexual abuse prevalence rate for practitioners: A review of child sexual abuse prevalence studies. Charleston, SC: Darkness to Light.

39. Finkelhor D, Shattuck A (2012) Characteristics of crimes against juveniles. Durham, NH: Crimes against Children Research Center.

40. Snyder HN (2000) Sexual assault of young children as reported to law enforcement: Victim, incident, and offender characteristics. A NIBRS Statistical Report. Washington, DC: U.S. Department of Justice, Office of Justice Programs.

41. Finkelhor D, Ormrod R, Turner HA, Hamby SL (2012) Child and youth victimization known to school, police, and medical officials in a national sample of children and youth. Juvenile Justice Bulletin, (No. NCJ 235394). Washington, DC: U.S. Department of Justice, Office of Juvenile Justice and Delinquency Prevention.

42. Kilpatrick DG, Ruggiero KJ, Acierno R, Saunders BE, Resnick HS, et al. (2003) Violence and risk of PTSD, major depression, substance abuse/dependence, and comorbidity: results from the National Survey of Adolescents. J Consult Clin Psychol 71: 692-700. [Crossref]

43. Girardet RG1, Lahoti S, Howard LA, Fajman NN, Sawyer MK, et al. (2009) Epidemiology of sexually transmitted infections in suspected child victims of sexual assault. Pediatrics 124: 79-86. [Crossref]

44. Acierno R, Kilpatrick DG, Resnick H, Saunders B, De Arellano M, et al. (2000) Assault, PTSD, family substance use, and depression as risk factors for cigarette use in youth: findings from the National Survey of Adolescents. J Trauma Stress 13: 381396. [Crossref]

45. Briere J, Elliott DM (2003) Prevalence and psychological sequelae of self-reported childhood physical and sexual abuse in a general population sample of men and women. Child Abuse Negl 27: 1205-1222. [Crossref]

46. Walker EA, Katon WJ, Hansom J, Harrop-Griffiths J, Holm L, et al. (1992) Medica and psychiatric symptoms in women with childhood sexual abuse. Psychosom Med 54 658-664. [Crossref]

47. Day A, Thurlow K, Woolliscroft J (2003) Working with childhood sexual abuse: A survey of mental health professionals. Child Abuse \& Neglect 27: 191-198.

48. Kendler KS, Bulik CM, Silberg J, Hettema JM, Myers J, et al. (2000) Childhood sexua abuse and adult psychiatric and substance use disorders in women: An epidemiologica and Cotwin control analysis. Archives of General Psychiatry 57: 953-959. [Crossref]

49. Felitti VJ, Anda RF, Nordenberg D, Williamson DF, Spitz AM, et al. (1998) Relationship of childhood abuse and household dysfunction to many of the leading causes of death in adults: The Adverse Childhood Experiences (ACE) Study. Am J Prev Med 14: 245-258. [Crossref]

50. Roustit C, Campoy E, Chaix B, Chauvin P (2010) Exploring mediating factors in the association between parental psychological distress and psychosocial maladjustment in adolescence. Eur Child Adolesc Psychiatry 19: 597-604. [Crossref]

51. Baglivio MT, Jackowski K, Greenwald MA, Howell JC (2014) Serious, violent, and chronic juvenile offenders. Criminology \& Public Policy 13: 83-116.

52. Bailey T, Peck D, Nelson S, English K, Pasinin-Hill D (1999) Juvenile delinquency prevention research: A study of youth in detention in Denver, October 1997-September 1998. Washington, DC: U.S. Department of Justice.

53. Davis L, Shlafer RJ (2017) Mental health of adolescents with currently and formerly incarcerated parents. J Adolesc 54: 120-134. [Crossref]

54. Evans-Chase M (2014) Addressing trauma and psychosocial development in juvenile justice-involved youth: A synthesis of the developmental neuroscience, juvenile justice and trauma literature. Laws 3: 744-758.

55. Hawkins JD, Herrenkohl T, Farrington D, Brewer D, Catalano R, et al. (2000) Predictors of youth violence. OJJDP Juvenile Justice Bulletin. Washington, DC: U.S. Department of Justice.

56. Snyder HN, Sickmund M (2006) Juvenile offenders and victims: 2006 national report. Washington, D.C.: National Center for Juvenile Justice, Office of Juvenile Justice and Delinquency Prevention.

57. Amstadter AB, Elwood LS, Begle AM, Gudmundsdottir B, Smith DW, et al. (2011). Predictors of physical assault victimization: Findings from the National Survey of Adolescents. Addict Behav 36: 814-820. [Crossref]
58. Atkinson A, Anderson Z, Hughes K, Bellis MA, Sumnall H, et al. (2009) Interpersonal violence and illicit drugs. London: Centre for Public Health.

59. Choenni V, Hammink A, van de Mheen D (2017) Association Between Substance Use and the Perpetration of Family Violence in Industrialized Countries: A Systematic Review. Trauma Violence Abuse 18: 37-50. [Crossref]

60. Dube SR, Anda RF, Felitti VJ, Croft JB, Edwards VJ, et al. (2001) Growing up with parental alcohol abuse: Exposure to childhood abuse, neglect, and household dysfunction. Child Abuse Negl 25: 1627-1640. [Crossref]

61. Eiden RD, Ostrov JM, Colder CR, Leonard KE, Edwards EP, et al. (2010) Parent alcohol problems and peer bullying and victimization: Child gender and toddler attachment security as moderators. J Clin Child Adolesc Psychol 39: 341-350. [Crossref]

62. Hanson RF, Self-Brown S, Fricker-Elhai A, Kilpatrick DG, Saunders BE, et al. (2006) Relations among parental substance use, violence exposure and mental health: the national survey of adolescents. Addict Behav 31: 1988-2001. [Crossref]

63. Lovallo WR, Farag NH, Sorocco KH, Acheson A, Cohoon AJ, et al. (2013) Early life adversity contributes to impaired cognition and impulsive behavior: studies from the Oklahoma Family Health Patterns Project. Alcohol Clin Exp Res 37: 616-623. [Crossref]

64. Walsh C, MacMillan H, Jamieson E (2003) The relationships between parental substance abuse and child maltreatment: Findings from the Ontario Health Supplement. Child Abuse Negl 27: 1409-1425. [Crossref]

65. Widom CS (1997) Child abuse, neglect, and witnessing violence. In D. M. Stoff, J. Breiling, \& J. D. Maser (Eds.), Handbook of antisocial behavior (pp. 159-170). Hoboken, NJ: John Wiley.

66. Kann L, McManus T, Harris WA, Shanklin SL, Flint KH, et al. (2018) Youth Risk Behavior Surveillance - United States, 2017. MMWR Surveill Summ 67: 1-114. [Crossref]

67. Irvine A (2010) "We've had three of them": Addressing the invisibility of lesbian, gay, bisexual and gender non-conforming youths in the juvenile justice system. Columbia Journal of Gender and Law 19: 675-701.

68. Irvine A, Canfield A (2015) The overrepresentation of lesbian, gay, bisexual, questioning, gender nonconforming and transgender youth within the child welfare to juvenile justice crossover population. Journal of gender, Social Policy \& the Law 24: 243-261.

69. Wilson BD, Jordan SP, Meyer IH, Flores AR, Stemple L, et al. (2017) Disproportionality and disparities among sexual minority youth in custody. $J$ Youth Adolesc 46: 1547 1591. [Crossref]

70. Administration on Children, Youth and Families (2016) Administration for Children and Families, Family and Youth Services Bureau: Street outreach program. Washington, D.C.: Administration on Chilren, Youth and Families.

71. Morton MH, Dworsky A, Samuels GM (2017) Missed opportunities: Youth homelessness in America. National estimates. Chicago: Chapin Hall at the University of Chicago.

72. Bender KA, Thompson SJ, Ferguson KM, Yoder JR, Kern L (2014) Trauma among street-involved youth. Journal of Emotional and Behavioral Disorders 22: 53-64.

73. Center for American Progress \& Movement Advancement Project (2016) Unjust: How the broken criminal justice system fails LGBTQ youth. Washington, D.C.: Center for American Progress.

74. Himmelstein KE, Brückner H (2011) Criminal-justice and school sanctions agains nonheterosexual youth: a national longitudinal study. Pediatrics 127: 49-57. [Crossref]

75. Mallory C, Sears B, Hasenbush A, Susman A (2014) Ensuring access to mentoring programs for LGBTQ youth. Los Angeles, CA: The Williams Institute, UCLA School of Law.

76. Teplin LA, Mericle AA, McClelland GM, Abram KM (2003) HIV and AIDS risk behaviors in juvenile detainees: Implications for public health policy. Am J Public Health 93: 906-912. [Crossref]

77. Hendershot CS, Magnan RE, Bryan AD (2010) Associations of marijuana use and sex related marijuana expectancies with HIV/STD risk behavior in high-risk adolescents. Psychol Addict Behav 24: 404-414. [Crossref]

78. Schmiege SJ, Broaddus MR, Levin M, Bryan AD (2009) Randomized trial of group interventions to reduce HIV/STD risk and change theoretical mediators among detained adolescents. J Consult Clin Psychol 77: 38-50. [Crossref]

79. Whaley AL (1999) Preventing the high-risk sexual behavior of adolescents: focus on HIV/AIDS transmission, unintended pregnancy, or both? $J$ Adolesc Health 24: 376382. [Crossref] 
80. Dembo R, Belenko S, Childs K, Wareham J, Schmeidler J (2009) Drug use and sexually transmitted diseases among female and male arrested youths. $J$ Behav Med 32: 129-141. [Crossref]

81. Kingree JB, Phan D (2002) Marijuana use and unprotected sexual intercourse among adolescent detainees: An event analysis. Criminal Justice and Behavior 29: 705-717.

82. Dembo R, Faber J, Cristiano J, DiClemente RJ, Krupa JM, et al. (2017) Health Risk Behavior Among Justice Involved Male and Female Youth: Exploratory, Multi-Group Latent Class Analysis. Subst Use Misuse 52: 1751-1764. [Crossref]

83. Johnston LD, O'Malley PM, Miech RA, Bachman JG, Schulenberg JE (2017) Monitoring the Future: National survey results on drug use, 2016 overview, key findings on adolescent drug use. Ann Arbor, MI: University of Michigan, Institute for Social Research.

84. Ritchwood TD, Ford H, DeCoster J, Sutton M, Lochman JE (2015) Risky Sexual Behavior and Substance Use among Adolescents: A Meta-analysis. Child Youth Serv Rev 52: 74-88. [Crossref]

85. Callahan TJ, Hooper AEC, Thayer RE, Magnan RE, Bryan AD (2013) Relationships between marijuana dependence and condom use intentions and behavior among justiceinvolved adolescents. AIDS Behav 17: 2715-2724. [Crossref]

86. Wu J, Witkiewitz K, McMahon RJ, Dodge KA, Conduct Problems Prevention Research Group (2010) A parallel process growth mixture model of conduct problems and substance use with risky sexual behavior. Drug Alcohol Depend 111: 207-214. [Crossref]

87. Griffin G, Germain EJ, Wilkerson RG (2012) Using a trauma-informed approach in juvenile justice institutions. Journal of Child \& Adolescent Trauma, 5: 271-283.

88. Riggs Romaine CL, Sevin Goldstein NE, Hunt E, DeMatteo D (2011) Traumatic experiences and juvenile amenability: The role of trauma in forensic evaluations and judicial decision making. Child \& Youth Care Forum 40: 363-380.

89. Webb JG (2017) An exploration of gender differences in high risk young offenders: Implications for assessment and service delivery. Electronic Thesis and Dissertation Repository.

90. Dembo R, DiClemente RJ, Brown R, Faber J, Cristiano J, et al. (2016) Health coaches: An innovative and effective approach for identifying and addressing the health needs of justice involved youth. Journal of Community Medicine \& Health Education 10: 2161-0711.

91. Melchior LA, Huba GJ, Brown VB, Reback CJ (1993) A short depression index for women. Educational and Psychological Measurement 53: 1117-1125.

92. Institute of Behavioral Research (2014) TCU drug screen V (TCUDS V). Ft. Worth, TX: Texas Christian University, Institute of Behavioral Research.

93. Tapert SF, Aarons GA, Sedlar GR, Brown SA (2001) Adolescent substance use and sexual risk-taking behavior. J Adolesc Health 28: 181-189. [Crossref]
94. Chacko M, Barnes C, Wiemann C, DiClemente R (2004) Implementation of urine testing for chlamydia (CT) and gonorrhea (NGC) in a community clinic. Journal of Adolescent Health 34: 146.

95. Radloff LS (1977) The CES-D scale: A self-report depression scale for research in the general population. Applied Psychological Measurement 1: 385-401.

96. Dembo R, Faber J, Cristiano J, Wareham J, DiClemente R, et al. (2018b) Psychometric evaluation of a brief depression measure for justice involved youth: A multi-group comparison. Journal of Child and Adolescent Substance Abuse.

97. Brown JL, Sales JM, Swartzendruber AL, Eriksen MD, DiClemente RJ, et al. (2014) Added benefits: Reduced depressive symptom levels among African-American female adolescents participating in an HIV prevention intervention. J Behav Med 37: 912-920. [Crossref]

98. Santor DA, Coyne JC (1997) Shortening the CES-D to improve its ability to detect cases of depression. Psychological Assessment 9: 233-243.

99. Muthén LK, Muthén BO (1998-2017) Mplus user’s guide, 8th edition. Los Angeles, CA: Muthén \& Muthén.

100. Dayton CM (1998) Latent class scaling analysis. Thousand Oaks, CA: Sage Publications.

101. Enders CK (2010) Applied missing data analysis. New York: Guilford Press.

102. Rubin DB (1987) Multiple imputation for nonresponse in surveys. New York: John Wiley \& Sons.

103. Schafer JL, Olsen MK (1998) Multiple imputation for multivariate missing-data problems: A data analyst's perspective. Multivariate Behav Res 33: 545-571. [Crossref]

104. Lo Y, Mendell NR, Rubin DB (2001) Testing the number of components in a normal mixture. Biometrik, 88: 767-778.

105. McLachlan G, Peel D (2000) Finite Mixture Models. New York: John Wiley \& Sons.

106. Nylund KL, Asparouhov T, Muthèn BO (2007) Deciding on the number of classes in latent class analysis and growth mixture modeling: A Monte Carlo simulation study. Structural Equation Modeling 14: 535-569.

107. Lee RD, Chen J (2017) Adverse childhood experiences, mental health, and excessive alcohol use: Examination of race/ethnicity and sex differences. Child Abuse \& Neglect 69: 40-48. [Crossref]

108. Roxburgh S, MacArthur KR (2014) Childhood adversity and adult depression among the incarcerated: Differential exposure and vulnerability by race/ethnicity and gender. Child Abuse Negl 38: 1409-1420. [Crossref]

Copyright: (2019 Dembo R. This is an open-access article distributed under the terms of the Creative Commons Attribution License, which permits unrestricted use, distribution, and reproduction in any medium, provided the original author and source are credited. 